\title{
A Política de Assistência Estudantil do Instituto Federal do Ceará do Campus de Tauá
}

\author{
Claudenira Cavalcante Melo \\ Universidade Estadual do Ceará - UECE \\ Profa. Dra. Isaurora Cláudia Martins de Freitas \\ Universidade Estadual do Ceará - UECE \\ https://revistas.uece.br/index.php/inovacaotecnologiasocial/article/view/4765
}

\begin{abstract}
Resumo
Este artigo tem como objetivo apresentar a análise da política de assistência estudantil do Instituto Federal de Educação, Ciência e Tecnologia do Ceará (IFCE) a partir da percepção dos/as discentes dos cursos técnicos integrados do campus Tauá. Tal problematização é parte da pesquisa de mestrado realizada de novembro de 2018 a setembro de 2019. 0 estudo, de natureza qualitativa, foi realizado através de pesquisas documentais, bibliográficas e de campo, onde se objetivou apreender a percepção dos/as alunos/as sobre a política de assistência estudantil do IFCE, bem como se a referida política contribui e de que forma contribui com a formação, com a permanência e com o êxito acadêmico e também avaliar a política e a atuação dos profissionais da equipe que a operacionaliza. Como técnicas de coletas de dados na pesquisa de campo foi utilizado o questionário, para traçar o perfil do/a aluno/a do IFCE campus Tauá e a técnica de grupo focal com os/as alunos/as dos cursos técnicos integrados, contando com a representação das cinco turmas existentes na instituição. Destacamos que as percepções apresentadas pelos/as alunos/as sobre a política de assistência estudantil do IFCE coadunam com a essência dessa política, qual seja, desenvolver programas, projetos e ações que contribuam para o desenvolvimento integral e integrado do/a estudante, a partir da compreensão do sujeito em sua totalidade, respeitando suas trajetórias e realidades e buscando suprir as suas necessidades.
\end{abstract}

Palavra-chave educação; assistência estudantil; IFCE; percepção.

\begin{abstract}
This article aims to present the analysis of the student assistance policy of the Federal Institute of Education, Science and Technology of Ceará (IFCE) from the perception of the students of the integrated technical courses on the Tauá campus. Such problematization is part of the master's research carried out from November 2018 to September 2019. The study, of a qualitative nature, was carried out through documentary, bibliographic and field research, where the objective was to apprehend the students' perception about IFCE's student assistance policy, as well as whether that policy contributes and how it contributes
\end{abstract}


to training, permanence and academic success and also to evaluate the policy and the performance of the professionals of the team that operates it. As techniques of data collection in the field research, the questionnaire was used, to outline the profile of the student of the IFCE campus Tauá and the focus group technique with the students of the integrated technical courses, counting on the representation of the five existing classes in the institution. We emphasize that the perceptions presented by the students about IFCE's student assistance policy are consistent with the essence of this policy, namely, to develop programs, projects and actions that contribute to the integral and integrated development of the student, starting from understanding of the subject in its entirety, respecting their trajectories and realities and seeking to meet their needs.

Key-word education; student assistance; IFCE; perception.

\section{Introdução}

A Assistência Estudantil configura-se estratégia de combate às desigualdades sociais e regionais, bem como instrumento para a ampliação e a democratização das condições de acesso e permanência dos jovens no ensino superior público federal (BRASIL, 2010). Surge no contexto da democratização do acesso à educação superior pública federal quando, a partir de 2003, políticas e programas específicos ${ }^{1}$ oportunizaram o ingresso de estudantes provenientes de camadas pobres da população brasileira nesse nível de ensino.

Essa democratização do acesso ao ensino superior público federal possibilitou uma heterogeneidade de público oriundo de um segmento social que até recentemente não tinha acesso à educação superior e que, normalmente, dispõe de condições de estudo limitadas e enfrenta dificuldades para a conclusão do curso no período regular, bem como para a sua permanência, tais como: gastos com transporte, alimentação, moradia, material didático; dificuldades de aprendizagem; necessidade de conciliar estudo e trabalho, dentre outras.

Nesse âmbito, evidenciou-se o desafio de implementar políticas públicas de apoio à permanência dos/as discentes. Assim, no final de 2007, através da Portaria no 39 do Ministério da Educação, o governo federal instituiu o Programa Nacional de Assistência Estudantil (PNAES), para o desenvolvimento de ações de assistência estudantil a partir de 2008. Mais tarde, em 2010, houve a edição do Decreto no 7.234/2010, instituindo o PNAES como uma política pública voltada para todas as instituições federais de ensino superior, incluindo os Institutos Federais de Educação, Ciência e Tecnologia que respondem por uma parcela da oferta da educação superior pública federal.

\section{O Instituto Federal do Ceará e o Campus de Tauá}

No Ceará, a Rede Federal de Educação Profissional, Científica e Tecnológica é constituída pelo Instituto Federal do Ceará (IFCE), através de por 33 (trinta e três) campi. A instituição passou de três unidades, em 2007, a trinta e três em 2019, sendo sete campi localizados na Região Metropolitana de Fortaleza e vinte e seis distribuídos pelo interior do Estado, a exemplo do campus de Tauá, criado em 20 de novembro de 2009 (IFCE, 2010).

Os Institutos Federais (IFs) têm personalidade jurídica de autarquias federais, detentoras de autonomia administrativa, patrimonial, financeira, didático-pedagógica e disciplinar, equiparados às universidades federais, para efeito da incidência das disposições

\footnotetext{
1 Como exemplos podemos citar: o Programa Universidade para Todos (PROUNI), o Fundo de Investimento ao Estudante de Ensino Superior (FIES), o Programa de Apoio a Planos de Reestruturação e Expansão das Universidades Federais (REUNI), a instituição e expansão da Rede Federal de Educação Profissional, Científica e Tecnológica, a Lei de Cotas - Lei n.o 12.711/2012, e a implantação do Sistema de Seleção Unificado (SISU).
} 
que regem a regulação, avaliação e supervisão das instituições e dos cursos de educação superior (BRASIL, 2008).

Os IFs são instituições de educação superior, básica e profissional, pluricurriculares e multicampi, especializados na oferta de educação profissional e tecnológica nas diferentes modalidades de ensino Portanto, o IFCE oferta cursos superiores (tecnológicos, bacharelados e licenciaturas) e de pós-graduação (especializações e mestrados), cursos de educação profissional técnica de nível médio e cursos de formação inicial e continuada ou de qualificação profissional nas modalidades presencial e a distância, observando o disposto na LDB - Lei no 9.394/96 e na sua regulamentação (BRASIL, 2008).

O campus de Tauá está situado a $340 \mathrm{~km}$ de Fortaleza, em um município - Tauá que até 2010, quando da realização do último censo pelo Instituto Brasileiro de Geografia e Estatística (IBGE), possuía 55.716 (cinquenta e cinco mil, setecentos e dezesseis) habitantes (IBGE, 2010). 0 campus oferta regularmente quatro cursos, sendo dois técnicos integrados ao ensino médio - Redes de Computadores (96 discentes) e Agropecuária (60 discentes) e dois superiores: Tecnologia em Telemática (117 discentes) e Licenciatura em Letras Português/Inglês (84 discentes), com um total de 357 alunos/as.

\section{O Programa Nacional de Assistência Estudantil e a Política de Assistência Estudantil do IFCE}

O PNAES representa um marco histórico de atenção à/ao estudante, instituído com a finalidade de prover os recursos necessários para o bom desempenho acadêmico e, assim, contribuir para reduzir as taxas de evasão e retenção, fenômenos que, historicamente, fazem parte dos debates e reflexões no âmbito da educação pública brasileira. Na análise de Vasconcelos (2010, p.608):

Essa conquista foi fruto de esforços coletivas de dirigentes, docentes e discentes e representou a consolidação de uma luta histórica em torno da garantia da assistência estudantil enquanto um direito social voltado para igualdade de oportunidades aos estudantes do ensino superior público.

O seu objetivo geral é ampliar as condições de permanência dos jovens na educação superior pública federal, enquanto os seus objetivos específicos consistem em: democratizar as condições de permanência dos jovens na educação superior pública federal, minimizar os efeitos das desigualdades sociais e regionais na permanência e conclusão da educação superior, reduzir as taxas de evasão e contribuir para a promoção da inclusão social pela educação (BRASIL, 2010).

De acordo com o PNAES, as ações de assistência estudantil deverão ser desenvolvidas pelas instituições nas seguintes áreas: moradia estudantil, alimentação, transporte, atenção à saúde, inclusão digital, cultura, esporte, creche, apoio pedagógico e acesso, participação e aprendizagem de estudantes com deficiência, transtornos globais do desenvolvimento e altas habilidades e superdotação.

Considerando as diretrizes norteadoras para ações de assistência estudantil, a partir da regulamentação do PNAES, os Institutos Federais começaram a normatizar suas políticas de assistência estudantis. Vejamos:

Em 2010, os institutos federais foram incluídos no Programa Nacional de Assistência Estudantil (PNAES), criado pelo governo federal para atender ao público das Universidades Federais. Além da inclusão no PNAES, os institutos federais, assim como as demais instituições que integram a Rede Federal de Educação Profissional, Científica e Tecnológica, tiveram um aumento significativo do aporte de recursos, na rubrica de assistência estudantil, a partir de 2011, induzindo o 
processo de elaboração e aprovação da política de assistência estudantil nessas instituições (TAUFICK, 2014, p. 183).

Embora seja considerado um importante avanço na consolidação das políticas de assistência ao estudante, o PNAES é criticado por estudiosos da área, que o consideram ação focalizada e seletiva e, por vezes, assistencialista:

\begin{abstract}
De todo modo, há que se reconhecer, a aprovação do PNAES pode ser interpretada como um marco e um avanço positivo na afirmação da política de Assistência Estudantil, a partir do qual a assistência ao estudante passa a se desenvolver sob uma nova perspectiva e concepção, mais aproximada à de direito social. Mas, sua plena realização como direito social impõe como principal desafio retirar o seu caráter seletivo e focalizado para que, de fato, a universalidade do acesso e permanência na educação superior seja uma realidade (SANTOS E FREITAS, 2014, p.198).
\end{abstract}

Baseando-se na literatura que concebe as políticas sociais como políticas que possuem uma dimensão assistencial, chegamos à compreensão que a Assistência Estudantil incorpora o caráter assistencial da política de educação (NASCIMENTO, 2013. p. 383).

No IFCE a política de assistência estudantil compreende a base sobre a qual se edificam programas, projetos e ações que contribuam para o desenvolvimento integral e integrado do/a estudante, com a finalidade de prover os recursos necessários para a superação dos obstáculos e dos impedimentos ao bom desempenho acadêmico e transita em todas as áreas dos direitos humanos, perpassando as ações de apoio pedagógico, de orientação profissional, de promoção da saúde, de conscientização de direitos, do exercício da cidadania, do fortalecimento do protagonismo e da autonomia dos sujeitos, do combate ao preconceito e à discriminação, de garantia de alimentação saudável etc. e destina-se a todos/as os/as estudantes regularmente matriculados/as (IFCE, 2015).

Referida política, regulamentada em 2015, através da Resolução CONSUP no 024, de 22 de junho, norteia-se pela legislação instituída em âmbito nacional, mas avança no sentido de ser um instrumento que contribui para o desenvolvimento integral e integrado dos/as discentes. 0 seu gerenciamento sistêmico é de responsabilidade da Diretoria de Assuntos Estudantis ${ }^{2}$ (DAE) e sua execução é de responsabilidade dos campi, sendo operacionalizada pelos profissionais da equipe multidisciplinar de assistência estudantil ${ }^{3}$, através de serviços e programas.

Os serviços, universais e contínuos, são em número de cinco: serviço social, serviço de saúde, serviço de alimentação e nutrição, serviço de psicologia e serviço de pedagogia. Já os programas, de caráter universal e específico, dividem-se nas seguintes áreas temáticas: trabalho, educação e cidadania; saúde; alimentação e nutrição; cultura, arte, desporto e lazer e auxílios estudantis. Esse consiste em conceder aos estudantes em situação de

2 De acordo com o artigo Art. 11 da Lei no 11.892/2008, que institui a Rede Federal de Educação profissional, Científica e Tecnológica, os Institutos Federais terão como órgão executivo a Reitoria, composta por 1 (um) Reitor e 5 (cinco) Pró-Reitores. Sendo assim, a estrutura administrativa do IFCE organiza-se através de uma Reitoria e de cinco Pró-reitorias: de Gestão de Pessoas; de Ensino; de Extensão; de Administração e Planejamento e de Pesquisa, Pós-graduação e Inovação, além de três Diretorias Sistêmicas com status de Próreitorias: de Tecnologia da Informação, Assessoria de Relações Internacionais e de Assuntos Estudantis, essa responsável pelo gerenciamento sistêmico da Política de Assistência Estudantil do IFCE.

3 De acordo com o Art. 7ํ da Resolução CONSUP no 24/2015, cada campus terá equipe multidisciplinar mínima constituída por pedagogo, assistente social, psicólogo, enfermeiro e nutricionista e estabelece que seja considerada equipe completa quando houver cargos preenchidos por profissionais das seguintes áreas, incluídos os da equipe mínima: educador físico, médico, odontólogo, assistente de aluno e técnico em assuntos educacionais (IFCE, 2015). 
vulnerabilidade socioeconômica auxílios financeiros com o objetivo de ampliar as condições de permanência, visando minimizar as desigualdades sociais (IFCE, 2015).

Evidenciamos, no entanto, que a referida política possui, dentre outras fragilidades, uma que compromete a sua execução de forma satisfatória - a insuficiência de recursos orçamentários - que reflete principalmente na execução do programa de auxílios estudantis, inviabilizando a concessão de auxílios aos estudantes de forma regular, como: auxílio moradia, transporte, alimentação, discentes mães/pais (auxílio para alunos/as pais ou mães de crianças até 12 anos de idade incompletos ou com deficiência), auxílio óculos, auxílio visitas/viagens técnicas, dentre outros.

Embora essa situação não seja comum a todos os campi do IFCE, atinge uma boa parte dos que têm menos tempo de funcionamento e que, portanto, vivenciam um processo de expansão da oferta educacional.

Diante do exposto, surgem as seguintes questões: Qual a percepção de assistência estudantil para os beneficiários dessa política? De que forma a Política de Assistência Estudantil contribui na formação discente? Como a Política de Assistência Estudantil contribui para a permanência e para o êxito acadêmico dos/as discentes? Que sugestões os/as discentes podem apresentar para a melhoria dessa política?

\section{O contexto e os sujeitos da pesquisa: o perfil dos/as alunos/as do IFCE campus Tauá e os Grupos Focais}

Para traçar o perfil do/a aluno/a do IFCE campus Tauá, foi elaborado um questionário com 17 (dezessete) perguntas e disponibilizado em meio eletrônico, através da plataforma Google Formulários, para que os mesmos pudessem respondê-lo, durante o período de 30 de agosto a 10 de setembro de 2019.

Do total de 357 (trezentos e cinquenta e sete) alunos/as matriculados/as, obtivemos 145 (cento e quarenta e cinco) respostas, sendo 55 (cinquenta e cinco) de alunos/as do curso técnico integrado em redes de computadores, 15 (quinze) do curso técnico integrado em agropecuária, 44 (quarenta e quatro) do curso superior de tecnologia em telemática e 31 (trinta e um) do curso de licenciatura em letras Português/Inglês.

Quanto ao perfil do/a aluno/a, constatamos que há um equilíbrio entre os sexos masculino e feminino, respectivamente 73 (setenta e três) e 72 (setenta e dois), predomínio de estudantes que têm como origem o município de Tauá (122), solteiros/as, na falta etária jovem ${ }^{4}$, pois a quase totalidade tem idade entre 15 e 26 anos, sem filhos, residindo com pais e irmãos, autodeclarados pardos ou brancos, tendo ingressado no IFCE através de ampla concorrência, apesar de a maioria ser proveniente de escola pública.

Quanto às famílias, predominam famílias com cinco ou mais membros, que residem em casa própria, na área urbana, sendo na maioria o pai e a mãe responsáveis pela renda familiar, com prevalência do trabalho formal, seguido de trabalho rural (agricultura e pecuária), com renda familiar de um a dois salários mínimos.

Os dados demonstram o grau de vulnerabilidade social de muitas famílias, pois há um número considerável que tem renda familiar de menos de um salário mínimo, como também é possível constatar a baixa renda per capita, tendo em vista que no universo pesquisado predominam famílias a partir de quatro membros.

A divisão da população brasileira em classes socioeconômicas é baseada em critérios da Associação Brasileira de Empresas de Pesquisa (Abep). A nova regra de classificação divide a população brasileira em seis estratos socioeconômicos denominados: A, B1, B2, C1, C2 e D-E, que leva em conta além da renda média familiar, a presença de itens no domicílio, como automóveis, geladeira, máquina de lavar, dentre outros (ABEP, 2018).

\footnotetext{
4 De acordo com a Lei no 12.852, de 05 de agosto de 2013, que institui o Estatuto da Juventude, são consideradas jovens as pessoas com idade entre 15 (quinze) e 29 (vinte e nove) anos de idade.
} 
Observando apenas o critério de renda é possível inferir que das cento e quarenta e cinco famílias dos/as alunos/as respondentes, cerca de cento e treze compõem as classes D e E, portanto, como já afirmamos, famílias com alto grau de vulnerabilidade social, demandando da política de assistência estudantil ações que promovam a permanência e a inclusão social no espaço escolar.

Com o objetivo de analisar a política de assistência estudantil do IFCE a partir da perspectiva dos discentes dos cursos técnicos integrados do campus de Tauá, foram realizados grupos focais com as cinco turmas, totalizando sete grupos, com número de participantes variando de oito a dezesseis pessoas. Os mesmos aconteceram em salas de aula, com as cadeiras organizadas em círculo e tiveram duração média de quarenta minutos, cujas falas foram gravadas com o consentimento dos/as participantes.

Em todos os grupos inicialmente foi realizada uma explanação sobre a pesquisa e seus objetivos, bem como foi explicitado que a discussão do grupo dar-se-ia a partir de perguntas-chaves, quais sejam: 1) 0 que significa assistência estudantil? 2) De que forma a política de assistência estudantil contribui na formação do/a aluno/a? 3) Como a política de assistência estudantil contribui para a permanência e para o êxito acadêmico? 4) Que críticas e/ou sugestões os/as discentes podem apresentar para a melhoria dessa política e dos serviços executados no campus?

A seguir, apresentaremos a percepção dos/as alunos/as dos cursos técnicos integrados do campus Tauá sobre a política de assistência estudantil do IFCE.

\section{A Política de Assistência Estudantil do IFCE na percepção dos/as alunos/as dos Cursos Técnicos Integrados do campus de Tauá: a voz dos sujeitos}

Sobre a percepção de assistência estudantil, os/as alunos/as referenciaram a assistência estudantil como uma rede de apoio para proporcionar o bem-estar do/a aluno e ajudá-lo a superar as possíveis dificuldades no percurso acadêmico. Vejamos:

\footnotetext{
Eu acho que a assistência estudantil é um ponto de bem-estar pro aluno, porque o diferencial do IF é justamente isso, porque nas outras instituições, outras escolas públicas, é muito difícil você ter todo esse aparato pro aluno, entendeu? Então eu acho que esse aparato é justamente para dar um bem-estar, uma melhor qualidade de vida pro aluno dentro da instituição e, se o aluno tiver bem fisicamente, tiver bem mentalmente, tiver bem consigo mesmo, eu acho que ele vai ter um bom desempenho (Aluno grupo focal 3).
}

Outros/as falaram da percepção de assistência estudantil como um lugar, um espaço de acolhida e cuidado:

\footnotetext{
Eu vejo a assistência estudantil como um meio, como um suporte ao aluno, porque, por exemplo, para nós que estudamos em tempo integral, é estressante, é cansativo passar o dia inteiro na escola e a assistência estudantil serve para manter a gente mais calmo, mais seguro, para meio que cuidar da nossa saúde física e mental e pra gente se sentir mais acolhido na escola, faz com que a gente se mantenha aqui e que a gente se sinta bem aqui (Aluno do grupo focal 3).
}

Outros/as revelaram a sua percepção de assistência estudantil como uma ferramenta que facilita o processo de adaptação na instituição e, consequentemente, melhor convivência no espaço escolar: 
A assistência estudantil ajuda também a gente a se adaptar a um novo mundo, porque a gente vem de uma realidade totalmente diferente daqui, com um cotidiano mais leve e quando a gente entra aqui, encontra uma realidade totalmente diferente, com um peso a mais, uma responsabilidade a mais e com esses recursos que a assistência estudantil oferece pra gente, a gente se sente abrigado, é como um refúgio pra nós, a gente pode derramar o que está sentindo e essas coisas, acho que é isso (Aluna do grupo focal 4).

Nas discussões dos grupos, alguns participantes apresentaram a sua percepção de assistência estudantil como estratégia de combate às vulnerabilidades sociais dos/as alunos/ e promoção da equidade:

E essa questão da alimentação é bem importante, porque como já foi citado, a questão social, querendo ou não, algumas pessoas não têm realmente o dinheiro pra se manter aqui sem ter a alimentação e, como foi citado, que poderia não ter almoço aqui, chegar a esse ponto, eu vi várias pessoas, assim, não poucas, mas várias pessoas falando que teria que sair daqui porque não têm condições de ir pra casa almoçar ou até mesmo não tem dinheiro porque não tem comida em casa (Aluna do grupo focal 4).

As falas dos/as alunos sobre a alimentação escolar refletem a ameaça que os bloqueios e contingenciamentos de recursos por parte do Ministério da Educação no primeiro semestre de 2019 tiveram sobre o fornecimento da merenda escolar e até do almoço, tendo em vista que no final do mês de junho e durante parte do mês de agosto de 2019 o fornecimento da merenda escolar foi suspenso e se cogitou a possibilidade de a instituição não ter recursos para arcar com o almoço dos/as alunos/as, o que não chegou a ocorrer.

Houve falas que relacionaram a assistência estudantil como instrumento para promover a permanência e o êxito acadêmico:

Eu vejo a assistência estudantil como um conjunto de profissionais que tem como objetivo viabilizar a permanência do aluno e o êxito dele ao ingressar no IF. (Aluna do grupo focal 7).

Quanto à segunda questão que orienta as discussões nos grupos - se a política de assistência estudantil contribui e de que forma contribui com a formação dos/as alunos/as - foi relatado que os serviços, de acordo com suas competências, contribuem de forma positiva na formação, sob diversos aspectos, como a promoção de uma formação cidadã, o exercício da cidadania, a consciência dos direitos e a formação do caráter:

A gente percebe um crescimento como cidadão. Eu tenho certeza que muita gente chegou aqui com um pensamento e vai sair daqui com outro (Aluno do grupo focal 1).

Eu acho que nas manifestações que a gente fez, na assembleia de alunos que teve, tudo que a gente fez de conscientização, partiu da assistência estudantil. Acho que se não fossem vocês, a gente não teria feito nada, ninguém teria aberto os olhos pra nada. Então, eu considero que a assistência estudantil é importante para conscientizar os alunos e orientar também, porque se fossem só os alunos, a gente não ia conseguir se organizar, fazer uma assembleia, ia ser uma bagunça (Aluna do grupo focal 3). 
Os/as alunos/as ressaltam a contribuição da assistência estudantil na formação do/a aluno/a em relação ao respeito ao outro, além de proporcionar um ambiente confortável para que o/a aluno/a possa dedicar-se aos estudos:

\begin{abstract}
Eu acho que um dos principais aspectos que a assistência contribuiu foi, principalmente, a interação com o próximo. Eu acho que com todo esse conjunto de profissionais nos ajuda a cada dia mais a como se comportar diante do nosso próximo, a como tratá-lo e isso é bom para a nossa convivência e formação do nosso caráter, pois eu acho que quando você aprende a conviver com o outro, você também aprende a respeitar o outro. Eu acho isso muito importante, você saber que não é só sua opinião, que os outros também têm opinião e você saber respeitar a opinião do outro (Aluna do grupo focal 5).
\end{abstract}

E eu acho também que essa questão de que a política de assistência estudantil, ela tenta proporcionar ao aluno ficar mais confortável pra essa questão do estudo porque, tipo, se não fosse o campus, a gente teria que ir, tipo, no CRAS pra conseguir alguma informação sobre assistência social, ir atrás, no PSF ou hospital, conseguir um atendimento com uma nutricionista ou com uma enfermeira, pra ter uma informação, pagar pra algum psicólogo privado pra poder desabafar, ou então, receber algum conselho ou orientação. Eu acho que isso proporciona muito mais pro aluno conforto e que ele possa focar na questão do estudo (Aluno do grupo focal 5).

Os/as alunos também ressaltaram a importância da assistência estudantil na formação, no que diz respeito ao apoio e orientação pedagógicos a alunos/as e também a pais/mães/responsáveis, realizados pelos profissionais da Coordenação TécnicoPedagógica:

\begin{abstract}
A Coordenação Técnico-Pedagógica é um dos setores que estão mais próximo dos pais. Assim, quando acontece alguma coisa com os alunos eles comunicam aos pais; se você precisa sair, você vai à sala deles e eles entram em contato com a família, e eles sempre cobram também dos pais, a presença na escola (Aluno do grupo focal 1).
\end{abstract}

Outros aspectos apontados pelos/as alunos/as de como a assistência estudantil contribui com a formação acadêmica referem-se à questão do combate à discriminação e ao preconceito e promoção de valores democráticos de respeito à diferença e à diversidade:

\begin{abstract}
Eu acho que uma das grandes coisas que a assistência estudantil proporcionou pra gente é o respeito à diversidade, porque eu venho de um colégio de freiras muito punho de ferro, muito mão de ferro, entendeu, em que os alunos que eram diferentes, os alunos que eram, digamos, afeminados, ou masculinizados, no caso das garotas, eles sofriam muito preconceito por ser um colégio de freiras, entendeu? Então, eu acho que uma das grandes coisas que a assistência estudantil mostra pra gente é que o belo é diferente e que pode ser sim respeitado, pode ser amado, entendeu? Então eu acho que um dos grandes pontos que a assistência estudantil proporciona pra gente é o respeito à diversidade e a todos os tipos de crenças, a todo tipo de concepção que você tem, a assistência estudantil respeita e valoriza bastante (Aluno do grupo focal 3).
\end{abstract}

A promoção da saúde mental também foi apontada nas falas dos/as alunos/as como contribuição importante da assistência estudantil na formação discente: 
Até na escola que eu estudei que era pública, existia essa coisa de, vamos mostrar que a nossa escola é a melhor. Aí os professores e outros profissionais nem se preocupavam tanto: ah, como será que os alunos tão se sentindo? Não, isso não importa. Criavam um projeto que iria incentivar a competitividade e é isso aí, a gente tinha que tirar nota boa. E outra coisa, o nosso ex-professor de História tava conversando com a gente, né, sobre o que realmente uma escola deveria ter e, nessa aula, ele falou que uma escola, além de professores de boa qualidade, deveria ter também psicólogos, enfermeiros e outras coisas, daí uma boa parte da sala falou: Psicólogo? Pra que psicólogo? É escola, não é hospital, ou seja, as pessoas não têm consciência dos próprios direitos, eles não entendiam: Pra quê psicólogo? Não precisa, entendeu? Aí o professor foi explicar que precisa por causa da saúde mental. E agora é a época que a gente mais fala de saúde mental e outras pessoas vêm dizer ainda que é frescura. No momento em que a humanidade está evoluindo, falando de saúde mental, outras pessoas vão dizer que é frescura (Aluna do grupo focal 3).

Em relação à permanência na instituição, os/as alunos/as, mesmo diante de diversas questões enfrentadas durante o seu percurso acadêmico, falam da importância da assistência estudantil para evitar uma possível evasão, seja com intervenções individuais ou coletivas:

Bom, eu acho que a maioria do pessoal que tá aqui, querendo ou não, sofreu um pouco de pressão no começo e, com certeza, pensou até em sair daqui. E uma das principais contribuições que a gente teve, ou foi procurar o psicólogo, ou foi algum recurso aqui do IF que sempre nos ajudou, foi tipo um norte pra gente, pra gente poder abrir mais a cabeça e não tomar uma decisão assim, precipitada. Então, eu acho que foi um recurso muito bom pra gente que contribuiu pra que a gente não desistisse do nosso futuro, assim como um colega falou (Aluna grupo focal 4).

Especificamente em relação ao êxito acadêmico, foi apontado que a assistência estudantil contribui para que o/a aluno/a tenha igualdade de oportunidades:

\begin{abstract}
Eu acredito que...todo mundo tem uma realidade diferente e quando você entra aqui no IF, essas realidades começam a se cruzar e quando você vem de uma escola pública, ou vem de uma escola privada, é totalmente diferente. Então, é como se a gente entendesse as dificuldades dos outros e essa política de assistência fizesse com que todo mundo chegasse num nível parecido ou igual, tipo assim, que fizesse com que as pessoas se preocupassem menos e focasse mais no estudo. Então, eu acredito que assim, é minha experiência, né, minha sala, ela tem um nível intelectual muito parecido e eu acredito que seja essa permanência, essa assistência que ajuda nisso, porque se não houvesse, as pessoas precisariam se preocupar com outras coisas do que só em estudar (Aluno do grupo focal 4).
\end{abstract}

Quanto à avaliação dos/as alunos/as sobre a política de assistência estudantil e seus serviços, as sugestões apresentadas foram no sentido da equipe de assistência estudantil realizar mais atividades em salas de aula, pois consideram que as intervenções são exitosas e propiciam uma convivência mais harmoniosa na instituição, bem como trabalhar mais a questão do respeito ao outro, combate ao bullying e a ansiedade, um distúrbio que tem aparecido com muita frequência no contexto escolar.

\title{
Considerações finais
}

Os dados demonstram que as famílias de uma parte considerável de alunos/as vivem em condições de vulnerabilidade social. Isso nos permite fazer duas considerações: primeiro, o quanto o programa de auxílios estudantis é necessário para a permanência 
dos/as estudantes na instituição; segundo, a falta de auxílios devido à escassez de recursos impacta diretamente na família que faz um esforço hercúleo para manter o/a filho/a na escola.

Quanto ao objetivo geral desta dissertação de analisar a política de assistência estudantil do IFCE a partir da percepção dos/as estudantes dos cursos técnicos integrados, constatamos que, para eles, assistência estudantil se define como:

- Uma rede de apoio para proporcionar o bem-estar do/a aluno e ajudá-lo a superar as possíveis dificuldades no percurso acadêmico;

- Lugar de acolhida e cuidado;

- Ferramenta que facilita o processo de adaptação na instituição e, consequentemente, melhor convivência no espaço escolar;

- Estratégia de combate às vulnerabilidades sociais dos/as alunos/ e promoção da equidade;

- Instrumento para promover a permanência e o êxito acadêmico.

Podemos afirmar que as percepções apresentadas coadunam com a essência dessa política no IFCE, qual seja, desenvolver programas, projetos e ações que contribuam para o desenvolvimento integral e integrado do/a estudante, a partir da compreensão do sujeito em sua totalidade, respeitando suas trajetórias e realidades e buscando suprir as suas necessidades.

Ratificamos a necessidade de se trabalhar as vulnerabilidades econômicas com os aspectos pedagógicos e psicossociais do/a estudante, pois é no contato diário com as realidades dos/as discentes que se identificam questões latentes que permeiam as relações sociais dos indivíduos, desde as suas necessidades mais básicas até situações mais complexas que perpassam relações familiares, dilemas sociais e culturais, que interferem no processo de ensino e de aprendizagem e que demandam intervenções qualificadas.

Assim, é imprescindível a articulação entre a assistência estudantil e o processo educativo, justificando-se para isso a importância de uma equipe multi e interdisciplinar, composta por assistentes sociais, psicólogos, pedagogos, enfermeiros, nutricionistas, entre outros, que trabalhe de modo integrado, a partir da compreensão do sujeito em sua totalidade.

É nesta perspectiva que entendemos a assistência estudantil, como uma ferramenta importante, articulada ao processo de ensino e aprendizagem, para minimizar os efeitos das desigualdades sociais, favorecendo a permanência e o êxito acadêmico e promovendo a inclusão social e a formação integral e integrada dos sujeitos, materializando um modelo de educação em que haja possibilidade concreta de transformação da realidade.

\section{Referências bibliográficas}

ABEP. Critério Brasil 2019. Disponível em < http://www.abep.org/criterio-brasil>Acesso em 14 out. 2019.

BRASIL. Decreto 7.234, de 19 de julho de 2010. Dispõe sobre o Programa Nacional de Assistência Estudantil - PNAES. Diário Oficial da República Federativa do Brasil, Poder Executivo, Brasília, DF, 20 jul. 2010. Disponível em:

<http://www.planalto.gov.br/ccivil_03/_Ato2007-2010/2010/Decreto/D7234.htm> Acesso em 22 dez. 2018. 
Lei no 11.892, de 29 de dezembro de 2008. Institui a Rede Federal de Educação

Profissional, Científica e Tecnológica, cria os Institutos Federais de Educação, Ciência e Tecnologia, e dá outras providências. Disponível em< http://www.planalto.gov.br/ccivil_03/_Ato2007-2010/2008/Lei/L11892.htm>Acesso em 28 nov.2019.

. Decreto no 7.234, de 19 de julho de 2010. Dispõe sobre o Programa Nacional de Assistência Estudantil (PNAES). Disponível em <http://www.planalto.gov.br/ccivil_03/_Ato2007-2010/2010/Decreto/D7234.htm> Acesso em 26 de outubro de 2018.

IBGE. Brasil em Síntese. Disponível em <https://cidades.ibge.gov.br/brasil/ce/taua/panorama> Acesso em 20 mar.2019.

INSTITUTO FEDERAL DE EDUCAÇÃO, CIÊNCIA E TECNOLOGIA DO CEARÁ. Relatório de Gestão 2010. Disponível em <https://ifce.edu.br/instituto/documentosinstitucionais/processo-de-contas_arquivos/2010/relatrio_de_gesto_2010.pdf > Acesso em 23 nov. 2018.

Aprova a Política de Assistência Estudantil do IFCE. Resolução $n^{\circ}$ 24/CONSUP/IFCE, de 22 de junho de 2015.

NASCIMENTO, Ana Paula Leite. Assistência Estudantil e Projeto Ético-político do Serviço Social: democratizar acesso ou permanência? Revista Eletrônica da Faculdade José Augusto Vieira, Ano VI - nº 08, setembro/2013.

SANTOS, Gabrielle dos; FREITAS, Leana Oliveira. Ensino superior público brasileiro: acesso e permanência no contexto de expansão. Argumentum, Vitória (ES), v. 6, n.2, p. 182-200, jul./dez. 2014.

TAUFICK, Ana Luiza de Oliveira Lima. Análise da Política de Assistência Estudantil dos Institutos Federais de Educação, Ciência e Tecnologia. 2013. Revista Brasileira de Políticas e Administração da Educação. Goiânia, v. 30, n. 1, p. 181-201, jan/abr. 2014. 